\title{
Broad bean wilt virus Causes Necrotic Symptoms and Generates Defective RNAs in Capsicum annuum
}

\author{
U. Lee, J. S. Hong, J. K. Choi, K. C. Kim,Y. S. Kim, I. S. Curtis, H. G. Nam, and P. O. Lim
}

First, sixth, seventh, and eighth authors: Department of Life Science, Pohang University of Science and Technology, Pohang 790-784, Korea; second and third authors: Division of Biological Environment, Kangwon National University, Chunchon 200-701, Korea; fourth author: Department of Agricultural Biology, Chonnam National University, Kwangju 500-757, Korea; and fifth author: The Biological Research Information Center, Pohang University of Science and Technology, Pohang 790-784, Korea.

Accepted for publication 6 September 2000.

\begin{abstract}
Lee, U., Hong, J. S., Choi, J. K., Kim, K. C., Kim, Y. S., Curtis, I. S., Nam, H. G., and Lim, P. O. 2000. Broad bean wilt virus causes necrotic symptoms and generates defective RNAs in Capsicum annuиm. Phytopathology 90:1390-1395.

A virus was isolated from hot pepper (Capsicum annuum cv. Hyang Chon) growing in Korea and displaying necrotic spots or streaks on leaves and stems followed by stunting and death of plants. Morphological and host range analyses of extracts from infected plants suggested that the causal agent of disease was a Broad bean wilt virus (BBWV), and the virus was tentatively named a Korean isolate of BBWV (BBWV-K). When the iso-

(CPs) of 44 and $22 \mathrm{kDa}$, corresponding to a large $\mathrm{CP}$ and a small $\mathrm{CP}$, respectively, were identified from the virus, and both reacted specifically with polyclonal antibody to BBWV 2. The complete nucleotide sequences of RNA 1 and RNA 2 of the isolate were determined from cDNA clones. The deduced amino acid sequence data from the putative proteins encoded by RNA 1 and 2 of the BBWV-K indicated a closer relationship with the isolates of BBWV 2 than BBWV 1. However, sequence comparison of the $5^{\prime}$ noncoding regions of the viruses differentiates BBWV-K from other BBWV 2 isolates. Another distinctive feature of the BBWV-K is that it generates defective RNAs in hot pepper exhibiting necrotic symptoms, which is the first report of defective RNAs in the Fabavirus genera of BBWVs.
\end{abstract} late was back-inoculated onto hot pepper plants, it induced symptoms similar to those of naturally infected hot pepper in the field. Two coat proteins

Broad bean wilt virus (BBWV) is a member of the genus Fabavirus. The virus is aphid-transmitted, has a broad host range, and has a worldwide distribution (26). BBWV causes serious disease in plants, such as wilt of broad beans, streak of peas, blight of spinach, and ringspot of petunia (26). The virus infects Capsicum annuum L. systemically, but has not been reported to induce severe symptoms $(4,8,26)$.

Several isolates of the BBWV have been described on the basis of host responses and gel immunodiffusion patterns $(3,13,23,24$, 28,30). Through serological studies, BBWV isolates are classified into two major groups, 1 and 2 (28).

BBWV has a bipartite genome, designated as RNA 1 (molecular weight $\approx 2 \times 10^{6}$ ) and RNA 2 (molecular weight $\approx 1.5 \times$ $10^{6}$ ) (3). Both genomic RNAs are separately encapsidated in two species of icosahedral shells with two distinctive polypeptides of molecular mass 41 to $45 \mathrm{kDa}$ (large coat protein, $\mathrm{L}-\mathrm{CP}$ ) and 23 to $27 \mathrm{kDa}$ (small coat protein, S-CP) $(3,26)$. Nucleotide sequences of RNA genomes from various BBWV isolates were recently determined $(9,10,15)$. The deduced amino acid sequence data indicate that BBWV RNA 1 encodes a single large protein containing a nucleoside triphosphate (NTP)-binding motif, a viral genome-linked protein (VPg), a protease, and a polymerase (15). BBWV RNA 2 is thought to encode a movement protein and two CPs $(9,10,15)$. Structural and nonstructural proteins are generated from the polyprotein precusor by protease cleavage. The molecular

Corresponding author: P. O. Lim; E-mail address: polim@ postech.ac.kr

Nucleotide sequences have been deposited in GenBank as Accession Nos. AF144234, AF104335, AF210058, and AF210059.

Publication no. P-2000-1013-02R

(C) 2000 The American Phytopathological Society
Additional keywords: classification, necrotic disease. data also provided information that aid in placing viruses into the BBWV 1 or BBWV 2 group (9). The conclusion drawn from the sequence analyses was consistent with that drawn from serological analyses, indicating that both parameters may be useful for BBWV classification.

In addition to genomic RNAs, small defective RNAs have been reported for a considerable number of viruses $(6,7,29)$. They arise spontaneously by deletions and rearrangements of the viral genome during infection. In some cases, these RNAs can have profound effects on symptom development $(6,7,19,22,29)$, though, no naturally occurring defective RNAs associated with any wildtype BBWVs have been described.

During a search for the agent that causes Pepper necrotic disease, we found a viral agent causing the premature death of young hot pepper (C. annuum cv. Hyang Chon) in commercial fields. The symptoms observed in naturally infected pepper plants included necrotic spots or streaks on the leaves and stems, with stunting and apical necrosis. These symptoms were different from symptoms caused by three major viruses of hot pepper (8): Pepper mild mottle virus (PMMV), Potato virus Y (PVY), and Cucumber mosaic virus (CMV). Because the disease mainly affects the emerging new shoots in early growth, fruit yield can be severely reduced. Our initial results on particle morphology and host responses indicated that the virus associated with the disease was likely to be a BBWV. Thus, it was tentatively designated as a Korean isolate of BBWV (BBWV-K).

In this report, we present the biological, serological, and molecular data demonstrating that the virus we have isolated is a causal agent for necrotic symptoms in hot pepper, and that the causal agent is a BBWV isolate that should be classified within the BBWV 2 group. Distinctive features of BBWV-K, such as its strong pathogenicity against hot pepper and the presence of defective RNA are also described. 


\section{MATERIALS AND METHODS}

Virus source and host range. BBWV-K was isolated from hot pepper (Capsicum annuum cv. Hyang Chon) with necrotic spots on leaves, necrotic streaks on stems, and apical necrosis. The virus was passed through three single chlorotic local lesion transfers on Chenopodium quinoa, which showed chlorosis 5 to 7 days after mechanical inoculation. Other BBWV isolates, originally obtained from spinach (BBWV-S, pv-0067), pepper (BBWV-G, pv-0221), and lettuce (BBWV-L, pv-0066), were provided by Deutsche Sammlung von Mikroorganismen und Zellkulturen GmbH (DSMZ, Braunschweig, Germany). All isolates were propagated and maintained in Chenopodium quinoa plants.

A host range comparison was performed by inoculating four hot pepper cultivars (Vp-Hy-203, Vp-Hy-164, Hyang Chon, and Golden Tower), one sweet pepper cultivar (Vp-Hy-103), and several indicator plants (Nicotiana benthamiana Domin., Chenopodium quinoa Willd., Spinacia oleracea, Petunia hybrida, and Vicia faba) with BBWV isolates. At least 12 plants from each species tested were mechanically sap-inoculated with each virus isolate in a temperature-controlled glasshouse at 22 to $25^{\circ} \mathrm{C}$. Plants were observed for the development of symptoms for up to 8 weeks, and then analyzed for the presence of virus by backinoculation onto healthy Chenopodium quinoa plants.

Electron microscopy. Infected leaf tissue was ground in $5 \mathrm{mM}$ potassium phosphate buffer ( $\mathrm{pH} 7.5$ ) with a glass rod. One drop of the sap extract was stained with $2 \%$ phosphotungstic acid and examined with an electron microsope (EM 109, Carl Zeiss Inc., Oberkochen, Germany). Particle measurements were made from micrographs of purified preparations of BBWV-K with CMV as a particle size standard.

Virus purification. Chenopodium quinoa plants infected with BBWV-K were harvested at 13 to 15 days postinoculation and used for virus purification. BBWV-K was purified with a slight modification of the standard Fabavirus purification protocol (3, 30). After rate-zonal sucrose density gradient centrifugation, the fractions containing virus were collected, and the virus was pelleted by centrifugation (70Ti rotor, Beckman Coulter, Fullerton, $\mathrm{CA})$ at $70,000 \times \mathrm{g}$ for $4 \mathrm{~h}$. Pellets were resuspended in $5 \mathrm{mM}$ potassium phosphate buffer ( $\mathrm{pH} 7.5)$ and used for subsequent analysis.

Immunoblot analysis. The total protein extracts from Chenopodium quinoa infected with the $\mathrm{BBWV}$ isolates, BBWV-K, BBWV-G, BBWV-L, and BBWV-S, were separated on a $10 \%$ sodium dodecyl sulfate (SDS)-polyacrylamide gel and transferred onto nylon membranes (Amersham Phamacia Biotech, Little Chalfont, England) by electroblotting, and the membranes were used for immunoblot analyses. Membranes were washed three times with TBS buffer (20 mM Tris ( $\mathrm{pH} 7.5), 150 \mathrm{mM} \mathrm{NaCl}$, and $0.5 \%$ Tween 20) and blocked for $4 \mathrm{~h}$ at $4^{\circ} \mathrm{C}$ in the same solution with $5 \%$ nonfat milk. Membranes were probed with rabbit polyclonal antibodies (immunoglobulin $\mathrm{G}$ fraction; $5 \mathrm{mg} / \mathrm{ml}$ ) against BBWV 1 (AS-0084) and BBWV 2 (AS-0207). Membranes were washed three times in TBS buffer and incubated with a horseradish peroxidase-conjugated secondary antibody (1:5,000 dilution; Amersham Phamacia Biotech). Complexes were visualized with an enhanced chemiluminescence kit, following manufacturer's instructions (Amersham Phamacia Biotech). The polyclonal antibodies were provided by DSMZ.

Microsequencing of the $\mathbf{N}$ terminus of purified CPs. Purified BBWV-K particles were separated into individual CPs by SDSpolyacrilamide gel electrophorosis (PAGE) and transferred to a polyvinylidon disulfide membrane (Amersham Phamacia Biotech) (11). Individual bands corresponding to each of the BBWV-K CPs were excised and subjected to $\mathrm{N}$-terminal sequencing by repetitive Edman cycles on a protein sequencer (ABI 470A, Applied Biosystems Inc., Foster City, CA).

RNA extraction and cDNA cloning. Viral RNAs were released from purified virus particles in resuspension buffer $(5 \mathrm{mM}$ potassium phosphate buffer ( $\mathrm{pH} 7.5)$, proteinase $\mathrm{K}(100 \mu \mathrm{g} / \mathrm{ml})$, $5 \mathrm{mM}$ EDTA, and $1 \% \mathrm{SDS}$ ) by incubating for $5 \mathrm{~min}$ at room temperature and $5 \mathrm{~min}$ at $95^{\circ} \mathrm{C}$. RNAs were immediately extracted twice with phenol/chroloform $(1: 1, \mathrm{vol} / \mathrm{vol})$ at room temperature and were precipitated with ethanol and ammonium acetate. The resulting pellets were resuspend in $10 \mathrm{mM}$ Tris- $\mathrm{HCl}$ ( $\mathrm{pH} 7.8)$, proteinase $\mathrm{K}(100 \mu \mathrm{g} / \mathrm{ml}), 5 \mathrm{mM}$ EDTA, and 1\% SDS. The solution was incubated at room temperature for $30 \mathrm{~min}$ and extracted twice with phenol/chroform/isoamyl alcohol (25:24:1, $\mathrm{vol} / \mathrm{vol})$ and once with chloroform/isoamyl alcohol (24:1, vol/vol). The RNAs were ethanol-precipitated, resuspended in RNase-free sterile-distilled water and used as template for cDNA cloning and primer extension.

Various strategies were used at different stages of the cloning process. The NotI/oligo deoxyribosylthymine (dT) 12-18-primed cDNAs were initially synthesized with a cDNA synthesis kit according to manufacturer's instruction (TimeSaver, Amersham Phamacia Biotech) and unidirectionally ligated into the EcoRI/ NotI site of pBluescript SK(+) (Stratagene Inc., La Jolla, CA). The constructs were transformed into the Escherichia coli strain JM 109. The largest clones, $1.8 \mathrm{~kb}$ (BK 78) for RNA 1 and $1.5 \mathrm{~kb}$ (BK 56) for RNA 2, were selected and their nucleotide sequences were determined.

The rest of the BBWV-K genome was cloned with a ZAPcDNA cloning kit (Stratagene Inc.) with the viral-specific oligonucleotide primer, BK RD-1 (5' GCGGCCGCCCCTCA GAAGTTCCGAGA ACCAAAGC $3^{\prime}$ ) for RNA 1 or BK CP (5' GCGGCCGCGCCAGAGTTCCCAGCTCCTTGCGG 3') for RNA 2, containing a NotI site (underlined) at the $5^{\prime}$ end. The $5^{\prime}$ terminal regions of RNA 1 and RNA 2 that were not covered by the cDNA clones, were cloned by RACE (rapid amplification of cDNA ends) method (5) with a cDNA amplification kit according to the manufacturer's instructions (Clontech Laboratories Inc., Palo Alto, CA). The RNA 1-specific primer was BK RN-1 (5' CAATATGATCTTTGAAATATATGG 3', complementary to nucleotides 215 to 238 of RNA 1) and its nested polymerase chain reaction (PCR) primer was BK RN-2 (5' GGTGCGCTTTAAATCACACTC 3', complementary to nucleotides 196 to 216 of RNA 1). The RNA 2 specific primer was BK MP-1 (5' CTAAGACTGCAACAAGCT CAGGACGC 3', complementary to nucleotides 215 to 240 of RNA 2) and its nested PCR primer was BK MP-2 (5' GCATTACAACACACTCAAAAC 3', complementary to nucleotides 196 to 216 of RNA 2). The RACE products were cloned into pGEM-T easy vector (Promega Corp., Madison, WI). Sequences were obtained in both directions from overlapping clones, and additional clones were obtained to confirm the regions of ambiguity. The extreme 5' end of BBWV-K RNAs were determined with primer extension (21) by oligonucleotide primer R1-5T (5' GAAAGTCACGCAGTAAC 3', complementary to nucleotides 143 to 159 of RNA 1 ) and MP1-5T (5' GAAAATTCCAAAGTATCTG 3', complementary to nucleotides 61 to 79 of RNA 2).

The nucleotides and the deduced amino acid sequences were compared with the GenBank database using the Blast program and DNASIS software package.

Northern blot hybridization. Total RNA from mechanically or naturally infected plants was extracted using TRI reagent (Sigma Chemical Co., St. Louis), separated on $1.2 \%$ agarose/formaldehyde gel and transferred onto nylon membranes (16). The blots were prehybridized and hybridized as described (16). Molecular weight of BBWV-K RNAs were determined by comparing their mobilities with those of the 0.24- to 9.5-kb RNA ladder (Gibco BRL, Rocksville, MD).

\section{RESULTS}

Host range. A serious disease showing necrotic spots or streaks on the leaves and stem, wilting of emerging fruit, and severe stunting of the whole plant was observed in hot pepper fields in 
the Kyungnam province of Korea during 1994 to 1995 . These symptoms were quite distinctive and had not been previously reported for hot pepper.

To investigate the causal agent of the disease, we analyzed plant extracts by electron microscopy. Isometric virus particles $(28 \mathrm{~nm}$ in size) were observed at high concentrations in infected hot pepper plants (data not shown). We then isolated isometric particles
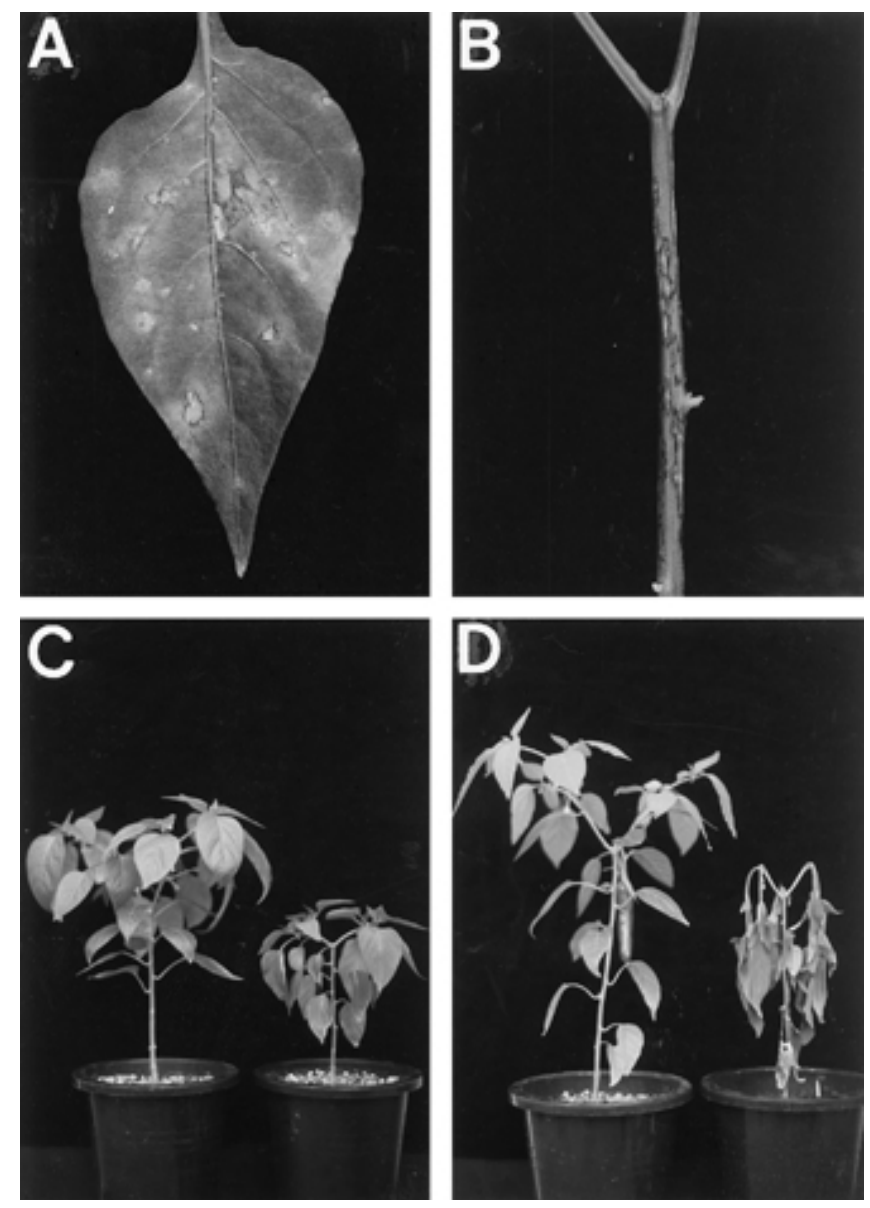

Fig. 1. Symptoms caused by Broad bean wilt virus of Korea (BBWV-K) in hot pepper, Capsicum annuum cv. Hyang Chon. A, Necrotic spots on an inoculated leaf 10 days after back-inoculation with BBWV-K. B, Necrotic streaks on stem 24 days after back-inoculation with BBWV-K. C, Stunting of whole plant 24 days after back-inoculation with BBWV-K. Left, mockinoculation; right, virus inoculation. D, Premature death of the whole plant 60 days after back-inoculation with BBWV-K. Left, mock-inoculation; right, virus inoculation from the diseased plant. When healthy hot pepper plants were mechanically inoculated with the purified particle, plants developed symptoms resembling those exhibited by field-grown plants. As shown in Figure 1, the virus induced necrotic spots on inoculated leaves of all tested cultivars of pepper 10 days postinoculation (Fig. 1A). This was soon followed by bright chlorotic streaks along the stem (Fig. 1B). Infected plants were stunted (Fig. 1C) and showed dark brown streaks on the stem and branches, and most of their flowers dropped before bearing fruit. Subsequently, apical necrosis of the newly emerging shoots was observed, and premature death of the whole plant occurred at 45 to 60 days postinoculation (Fig. 1D). The resulting development of symptoms in the pepper plants suggested that the isometric particle was the causal agent of a severe necrotic disease.

To study the host range of the presumed isometric virus, we examined the symptom development in 10 indicator plants (Table 1 ). The virus induced systemic mosaic symptoms in $S$. oleracia, $P$. hybrida, and $N$. benthamiana. In bean, it induced necrotic patches on inoculated leaves, followed by veinclearing and wilting of the upper leaves. In Chenopodium quinoa, it induced large chlorotic spots on inoculated leaves 5 days postinoculation and later leaf chlorosis and apical necrosis on the upper leaves. The induced symptoms in these indicator plants were quite similar to symptoms previously described for BBWV isolates $(13,23,24,26,30)$. However, the symptoms induced by the virus in hot pepper were significantly different from those induced by the BBWVs, which infect pepper plants systemically without any detectable local symptoms (Table 1). Although differences in symptom development in hot pepper cultivars were observed, we tentatively classified the hot pepper-infecting isometric virus as an isolate of BBWV (BBWV-K), because the virus resembled the BBWV isolates in morphology and host response in most of the indicator plants tested.

Serology. To determine the taxonomic position of the virus by serology, immunoblot analyses were performed on extracts to detect the CPs. For these analyses, BBWV-L was included as a positive control for group 2, and BBWV-G and BBWV-S for group 1. From the purified BBWV-K virus particles, two CPs, one $\mathrm{S}-\mathrm{CP}$ of approximately $22 \mathrm{kDa}$ and one L-CP $44 \mathrm{kDa}$, were observed by SDS-PAGE (Fig. 2A). The CPs of BBWV-K reacted strongly with the polyclonal antibody raised against BBWV 2 (AS-0207) (Fig. 2B), but they did not react with polyclonal antibody raised against BBWV 1 (AS-0084) (Fig. 2C). None of the polyclonal antibodies used in this analysis reacted with leaf extracts from healthy plants. This result indicates that the isolated isometric virus belongs to the BBWV 2 group of the BBWV isolates.

Characterization of BBWV-K genomic RNA. Complementary DNA clones were generated from BBWV-K and the

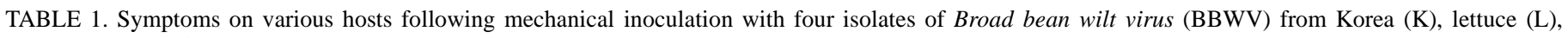
pepper $(\mathrm{G})$, and spinach $(\mathrm{S})^{\mathrm{a}}$

\begin{tabular}{|c|c|c|c|c|c|c|c|c|}
\hline \multirow[b]{2}{*}{ Host } & \multicolumn{2}{|c|}{ BBWV-K } & \multicolumn{2}{|c|}{ BBWV-L } & \multicolumn{2}{|c|}{ BBWV-G } & \multicolumn{2}{|c|}{ BBWV-S } \\
\hline & Inoculated & Infected & Inoculated & Infected & Inoculated & Infected & Inoculated & Infected \\
\hline \multicolumn{9}{|l|}{ Sweet pepper } \\
\hline Vp-Hy-103 & NS & $\mathrm{M}, \mathrm{SN}, \mathrm{D}$ & $\mathrm{L}$ & MM & $\mathrm{L}$ & MM & $\mathrm{L}$ & M \\
\hline \multicolumn{9}{|l|}{ Hot pepper } \\
\hline Vp-Hy-203 & NS & $\mathrm{M}, \mathrm{SN}, \mathrm{D}$ & $\mathrm{L}$ & MM & $\mathrm{L}$ & MM & $\mathrm{L}$ & M \\
\hline Vp-Hy-164 & NS & $\mathrm{M}, \mathrm{SN}, \mathrm{D}$ & $\mathrm{L}$ & MM & $\mathrm{L}$ & MM & $\mathrm{L}$ & M \\
\hline Hyang Chon & NS & $\mathrm{M}, \mathrm{SN}, \mathrm{D}$ & $\mathrm{L}$ & MM & $\mathrm{L}$ & MM & $\mathrm{L}$ & M \\
\hline Golden Tower & NS & M, SN, D & $\mathrm{L}$ & $\mathrm{MM}$ & $\mathrm{L}$ & $\mathrm{MM}$ & $\mathrm{L}$ & M \\
\hline Chenopodium quinoa & CS & CS, SN, D & CS & CS, SN, D & CS & CS, SN, D & $\mathrm{CS}$ & SN, D \\
\hline Nicotiana benthamiana & $\mathrm{M}$ & $\mathrm{M}$ & M & $\mathrm{M}$ & $\mathrm{M}$ & $\mathrm{M}$ & M & M \\
\hline Petunia hybrida & RS & M & RS & M & RS & M & RS & $\mathrm{M}$ \\
\hline Spinacia oleracia & CS & M & $\mathrm{CS}$ & M & CS & M & $\mathrm{CS}$ & M \\
\hline Vicia faba & NP & $\mathrm{VC}, \mathrm{W}$ & NP & $\mathrm{VC}, \mathrm{W}$ & NP & $\mathrm{VC}, \mathrm{W}$ & NP & $\mathrm{VC}, \mathrm{W}$ \\
\hline
\end{tabular}

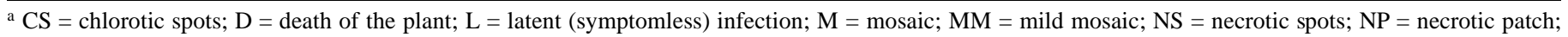

$\mathrm{RS}$, ringspot; $\mathrm{SN}=$ shoot necrosis; $\mathrm{VC}=$ veinclearing; $\mathrm{W}=$ wilt. 
nucleotide sequences of the overlapping cDNA clones, along with that of the extreme $5^{\prime}$ end of BBWV RNAs, as determined by primer extension, were determined. The full size of BBWV-K RNA 1 and RNA 2 was 5,989 and 3,589 nt in length, respectively, excluding the 3 ' poly (A) tracts (Fig. 3 ).

RNA 1 contained a single large open reading frame (ORF) starting with an AUG codon at position 266 to 268 and terminating with an UGA codon at position 5878 to 5880 . RNA 2 contained a single large ORF starting with an AUG codon at position 213 to 215 and terminating with an UAA codon at position 3408 to 3410 . The $5^{\prime}$ and $3^{\prime}$ noncoding regions (NCR) of BBWV-K RNA 1 were 265 and 109 nt in length, respectively. The corresponding regions in RNA 2 were 212 and 179 nt in length, respectively (Fig. 3).

When the deduced amino acid sequences of the putative proteins in RNAs 1 and 2 from the BBWV-K were compared with sequences in the available database, the highest sequence identity (89\%) was with BBWV-MB7 isolate, and a slightly lower sequence identity $(78 \%)$ was obtained with BBWV-IP. These two BBWV isolates belong to the BBWV 2 strain, and thus, the molecular data were consistent with our serological data, indicating that BBWV-K should be categorized as a group 2 isolate.

The large ORF in BBWV-K RNA 1 encodes a 210-kDa polyprotein. Alignments of the deduced amino acid sequences of the polyprotein from BBWV-K with those of BBWV-MB7 (15) showed $89 \%$ identity. By analogy with the BBWV-MB7, four putative proteins: the NTP-binding protein $(1,15)$, the small VPg (14), the protease $(2,15,27)$, and the RNA-dependent RNA polymerase $(\operatorname{RdRp})(15,17)$, were identified in the polyprotein of the BBWV-K RNA 1, and the conserved motifs for each protein were also found (Fig. 3). This result implies that the genomic organization of the RNA 1 of BBWV-K is similar to those of other BBWV isolates. When we compared the $5^{\prime}$ NCR of RNA 1 from these two viruses, the $5^{\prime} \mathrm{NCR}$ of BBWV-K was slightly longer than the $5^{\prime}$ NCR of BBWV-MB7, showing several deletions and insertions of 5, 9, and 12 nts (Fig. 4A). The sequence identities of the $5^{\prime}$ and $3^{\prime}$ NCR between these two sequences were 70.2 and $82 \%$, respectively.

RNA 2 of BBWV-K encoded a 119-kDa polyprotein. The deduced amino acid sequences showed significant identities to those of the movement protein and L-CP of BBWV-MB7 (94 and $96 \%$, respectively) (15) and BBWV-IP (87 and 94\%, respectively) (9; Table 2). In order to locate the CP coding sequences, we

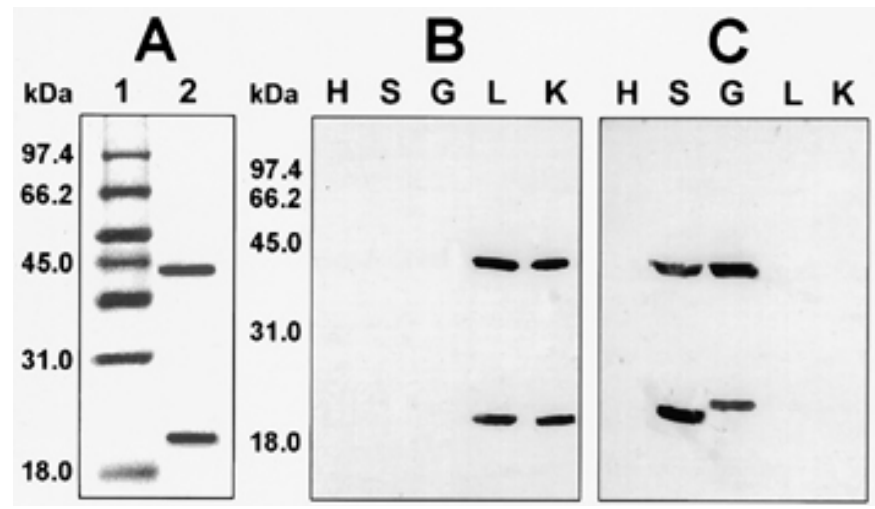

Fig. 2. Analysis of the coat proteins of Broad bean wilt virus of Korea (BBWV-K). A, Sodium dodecyl sulfate-polyacrylamide gel electrophoresis (SDS-PAGE) analysis of BBWV-K. Purified virus was subjected to $10 \%$ SDS-PAGE and proteins stained with Coomassie brilliant blue. Lane 1, molecular-weight markers (Bio-Rad Laboratories, Hercules, CA) and numbers at left indicate molecular weights; lane 2, coat proteins from the purified virus of BBWV-K. B and $\mathbf{C}$, Immunoblot analysis of total proteins extracted from healthy plants $(\mathrm{H})$ and plants infected with BBWV-S (S), BBWV-G $(\mathrm{G})$, BBWV-L (L), and BBWV-K (K) and probed with polyclonal antibodies to BBWV B, serotype 2 , and $\mathbf{C}$, serotype 1 . analyzed the N-terminal regions of L-CP and S-CP by microsequencing. The N-terminal amino acid sequences of the CPs were GLMEEDVLNVQTNTFAIE for L-CP and AHATPKDFSSV RFVM for S-CP. When we compared the CP N-terminal amino acid sequences with the amino acid sequences deduced from the nucleotide sequence, a perfect match occurred. From these data, it was determined that two CPs were encoded at the end of the $\mathrm{C}$ terminus of the polyprotein and that the L-CP coding region is located $5^{\prime}$ of the S-CP coding region (Fig. 3). Subsequently, the $\mathrm{CP}$ cleavage sites, glutamine-glycine $(\mathrm{Q}-\mathrm{G})$ and glutamine-alanine (Q-A) of the 119-kDa protein, were predicted. The predicted sizes for the two proteins were 44 and $22 \mathrm{kDa}$, which is in agreement with the expected molecular weights of the CPs estimated by SDS-PAGE (Fig. 2).

Comparison of the predicted amino acid sequence of the BBWV-K CP-coding region with the corresponding sequence of other BBWV 2 isolates revealed 88 to $97 \%$ sequence identity (Table 2), but when compared with BBWV 1 isolates, the sequence identity was 40 to $50 \%$ (data not shown). Similarly to RNA 1, the nucleotide sequences of the $5^{\prime}$ NCR (Fig. 4B) and 3' NCR from the BBWV-K RNA 2 share lower identities (70 to $88 \%$ ) with those of other BBWV isolates (Table 2).

Characterization of small defective RNAs. When the blot of total RNA from naturally infected pepper plants was probed with cloned cDNAs from the 3' terminal region of BBWV-K RNA 1 or RNA 2, the probes hybridized strongly with their respective homologous genomic RNA. In addition, two smaller and less abundant RNAs were detected (Fig. 5A and C).

To determine the nature of the smaller RNAs, cDNA clones were generated from these two small RNAs and their sequences were determined. Analysis of the sequences demonstrated that they had the general form of defective RNAs that has been described in several other plant virus groups $(6,19,20,22,29)$. One defective RNA-A is composed of 305 nts corresponding to the $3^{\prime}$ terminus and 647 nts corresponding to the $5^{\prime}$ end of the BBWV-K genomic RNA 2 (Fig. 5B). The sequence identity between the $3^{\prime}$ region and the $5^{\prime}$ end of the defective RNA-A molecule and the corresponding regions of the BBWV-K genomic RNA 2 were 94 and 90\%, respectively (Fig. 5B). The 266-nt small part of defective RNA-B is from the $3^{\prime}$ portion of the BBWV-K genomic RNA 1, and the remaining fragment of $367 \mathrm{nt}$ represents the 5'

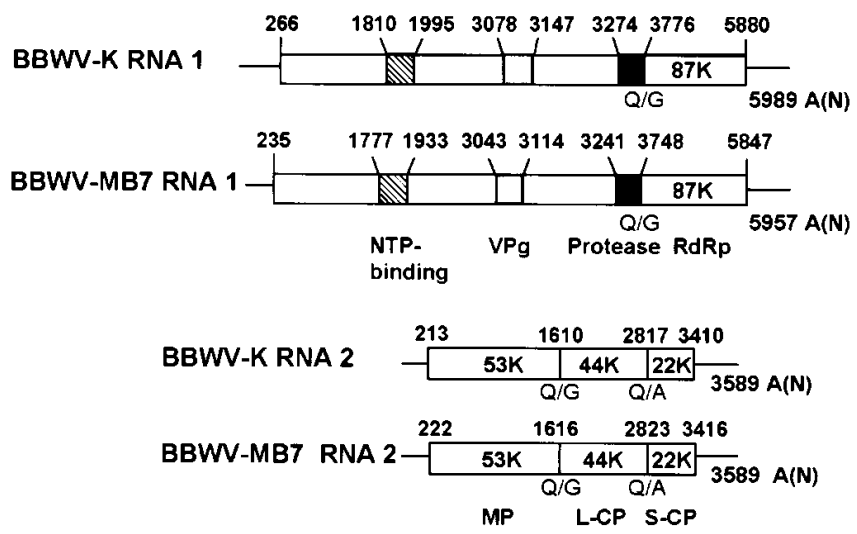

Fig. 3. Comparison of the genomic organization of the RNAs from Broad bean wilt virus of Korea (BBWV-K) and BBWV-MB7 (16). Open reading frames are indicated as boxes according to the putative translation products. Numbers above the boxes indicate the nucleotide number in each RNA at that position. Possible cleavage sites for polyprotein processing are shown by slashes between single letter amino acid designations. Crosshatched boxes indicate conserved amino acids regions for nucleoside triphosphate (NTP)binding motifs (GxxGxGKS/Tx $x_{42} \mathrm{DD}$ ). The white boxes indicate a putative viral-linked protein ( $\mathrm{VPg})$ motif $\left(\mathrm{E} / \mathrm{Dx}_{2-3} \mathrm{Yx}_{3} \mathrm{RNx}_{4-5} \mathrm{R}\right)$. The black boxes indicate amino acids representing the catalytic triad of a protease (4). MP, putative movement protein; L-CP, large coat protein; S-CP, small coat protein; and RdRp, putative RNA dependent RNA polymerase. 
terminus of RNA 1 (Fig. 5D). The $5^{\prime}$ and $3^{\prime}$ regions showed 97 and $91 \%$ identity, respectively, with the corresponding regions in the BBWV-K genomic RNA 1 (Fig. 5D).

\section{DISCUSSION}

In this paper, we determined the biological, serological, and molecular characteristics of a virus causing necrotic symptoms in hot pepper. The molecular and serological data presented in this study clearly indicated that the causal agent is an isolate of BBWV, belonging to the BBWV 2 group. The virus was designated as BBWV-K.

To date, two BBWV isolates were known to infect hot pepper, but neither of them caused necrotic disease $(8,26)$. In contrast to these viruses, the BBWV-K induced necrotic symptoms in hot pepper in our study. This finding is significant, because it is a feature that differentiates BBWV-K from all other BBWV isolates analyzed so far. Furthermore, the results imply that protection from such a serious disease can be easily accomplished, because control of BBWV-K alone is possible, for example, by adapting the viral CP protein gene-mediated protection strategy $(12,18)$, after the virus is characterized at the molecular level.
Molecular studies on BBWV isolates have only been initiated recently, with the entire genome sequence known for only one isolate, BBWV-MB7 (15). The RNA 2 sequence from BBWV-IP3 (9) and the 3'-terminal sequence from five other isolates (9) belonging to the BBWV 1 or 2 have also been reported. Analysis of the complete genome sequence of BBWV-K and its comparison with those of other BBWV isolates revealed that in both genetic organization and deduced amino acid sequence, BBVW-K was similar to these BBWV isolates. Seven processed proteins predicted from BBWV-K RNAs had 83 to $97 \%$ amino acid sequence identity with the corresponding proteins of BBWV isolates belonging to the BBWV $2(9,15)$. Moreover, in the comparison of $\mathrm{CP}$ genes, which are a useful taxonomic marker, the average amino acid identity between BBWV-K and isolates of the BBWV 2 group (9) was $92 \%$. These values are, thus. within the range proposed for classification of strains of the same virus (25). When the sequence comparison was extended to the $5^{\prime}$ and $3^{\prime}$ NCRs, which are good phylogenetic markers for closely related isolates, lower identities (70 to $93 \%$ ) were observed, implying that the BBWV-K is distinct from other BBWV 2 viruses. Thus, together with the results of the different symptom development in hot pepper, these molecular data suggest that the BBWV-K is a new BBWV 2 isolate.

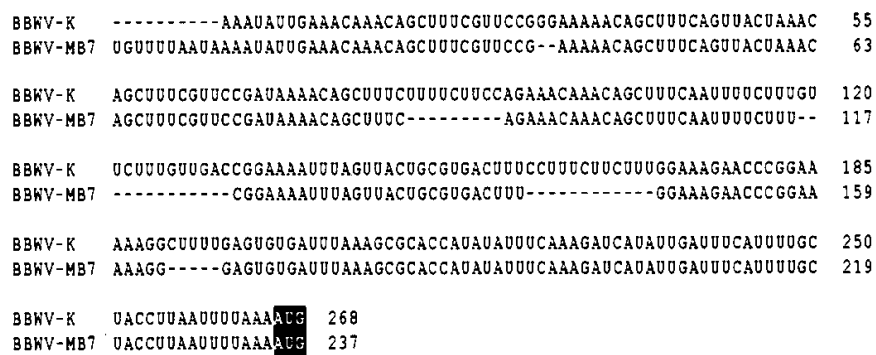

BBWV-K UACCUUAAUUOOAAART 268

BBGV-K BBWV-MBT OGUOOOAAUAAARUAUAAAACAAACAGCUOOCGUDCCGAGAAAADAGCUUUCAGUUAC-AAAAO 64

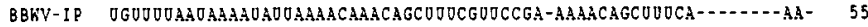

BBKV-K AGCOOOCGGCOACAAAACAGCODOCAGAUACOUUGGAAUUOUCAAAOUGAACCCGGASAAAGGGA $\quad: 01$ BBWV-MBT AGCUUUCAGOUUCACAACAGCOUOCAGACACOUUG-AAGUUUCAAAOUGAACCCGGAAAAGGGG 228

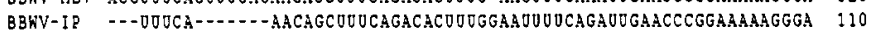

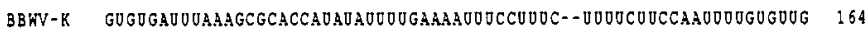

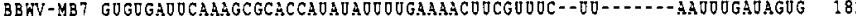
BBWV-IP GUGDGAUUAAAGCGCACCADAUCAOUUGAAAAUOUCGUUOUGAUCOAGCODOCCUOGCUAAUG 175

BBWV-K UUCUOGUUGACGUAUUACACAGUCAAAODUGAGUUUUGaGUUGUUGUAAJG 215 BBWV-MB7 - - - CAUAAD-CAOUCGGAAODUOGA-DOOCGGAUAOGUDGOAATG 224

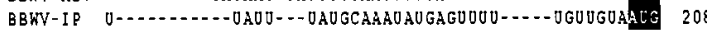

Fig. 4. Multiple alignment of the $5^{\prime}$ noncoding region of A, RNA 1 and $\mathbf{B}$, RNA 2 of Broad bean wilt virus of Korea (BBWV-K) and other BBWV isolates. The sequences of BBWV-MB7 (16) and IP (9) have been published. Dark-shaded characters indicate the first ATG codon for translation initiation. Hyphens are used to indicate gaps introduced to maximize the alignment.

\section{A}
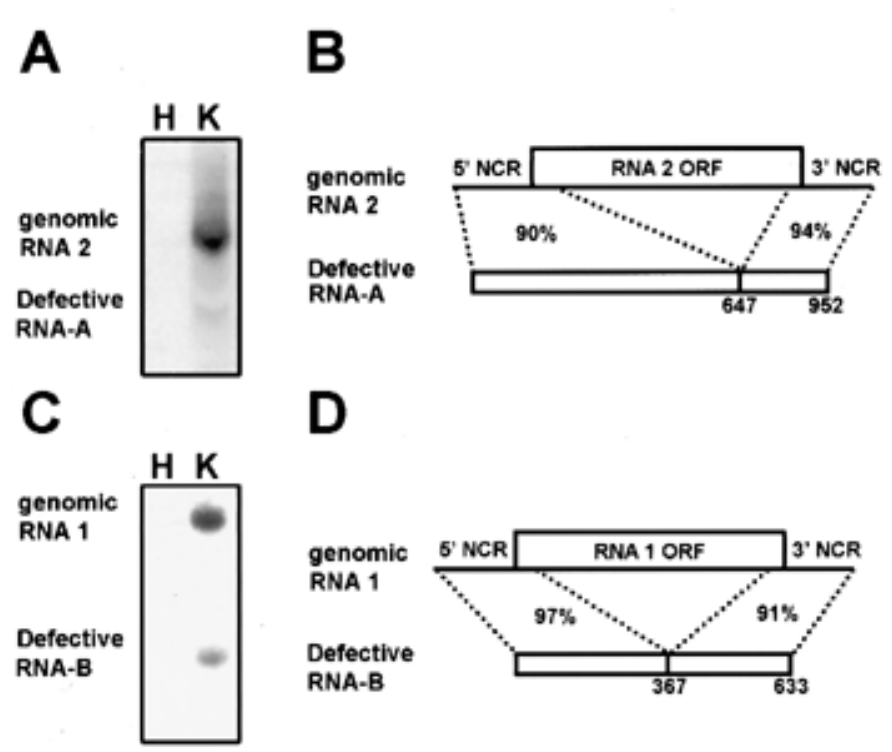

Fig. 5. Molecular characterization of defective RNA-A and defective RNAB. A and C, Northern blot analysis of total RNA extracted from healthy plants $(\mathrm{H})$, or plants naturally infected with Broad bean wilt virus of Korea (BBWV-K) (K). Total RNAs were separated on $1.2 \%$ agarose/formaldehyde gels and transferred onto nylon membranes. The membranes were hybridized with cDNA probes complementary to $\mathbf{A}$, defective RNA-A, or $\mathbf{C}$, defective RNA-B, washed, and exposed to X-ray film for $16 \mathrm{~h}$. The positions of genomic RNAs and defective RNAs are indicated on the left. Diagram of the general structure of B, defective RNA-A, and D, defective RNA-B derived from BBWV-K genomic RNAs, respectively. Numbers below the genomic RNAs show the percentage of identical nucleotides when genomic RNAs and defective RNAs were compared.

TABLE 2. Sequence identities between gene products or noncoding regions (NCRs) of Broad bean wilt virus of Korea (BBWV-K) and other BBWV isolates ${ }^{\mathrm{a}}$

\begin{tabular}{|c|c|c|c|c|c|c|c|c|c|c|c|}
\hline \multirow[b]{2}{*}{ Isolate $^{b}$} & \multicolumn{7}{|c|}{ Amino acid sequence identity with BBWV-K gene products } & \multicolumn{4}{|c|}{ Nucleotide sequence identity with BBWV-K NCRs } \\
\hline & NTP-binding & $\mathrm{VPg}$ & Protease & $\operatorname{RdRp}$ & MP & LCP & SCP & $5^{\prime}$ RNA 1 & $5^{\prime}$ RNA 2 & 3' RNA 1 & $3^{\prime}$ RNA 2 \\
\hline BBWV-MB7 & 100 & 100 & 97 & 96 & 94 & 96 & 97 & 70.2 & 82 & 93 & 83 \\
\hline BBWV-IP & - & - & - & - & 87 & 94 & 92 & - & 81 & - & 70 \\
\hline BBWV-E & - & - & - & - & - & 95 & 96 & - & - & - & 88 \\
\hline BBWV-L & - & - & - & - & - & 91 & 90 & - & - & - & 70 \\
\hline BBWV-1-2 & - & - & - & - & - & 90 & 88 & - & - & - & 72 \\
\hline
\end{tabular}

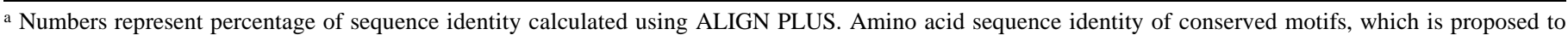
be core regions of NTP-binding, viral genome-linked protein (VPg), and movement protein (MP). Amino acid sequence identity of complete regions of RNA dependent RNA polymerase (RdRp), large coat protein (L-CP), and small coat protein (S-CP).

${ }^{\mathrm{b}}$ Reference for sequences: BBWV-MB7 (15), BBWV-IP, -E, -L, and -1-2 (8). 
One noticeable feature of the BBWV-K found in this study is that defective RNAs are present in hot pepper infected by this virus. To our knowledge, this is the first report that describes the presence of defective RNAs in BBWV-infected plants.

The presence of defective RNAs in virus-infected plants can reduce the accumulation of the helper virus and induce attenuation $(7,22)$, intensification (19), or result in no modifications in symptom expression $(6,29)$. According to our RNA blot analysis, defective RNAs were present at very low concentrations, compared with BBWV genomic RNAs. In addition, defective RNAs were consistently found in hot pepper plants showing severe necrotic symptoms. These observations may indicate that defective RNAs found in BBWV-K-infected hot pepper plants are not associated with symptom attenuation. Further analyses are necessary, however, to assign biological functions to particular BBWV-K defective RNA molecules in pepper. The development of infectious clones of the virus and the defective RNA will help to examine its biological properties, providing definitive evidence on whether the defective RNAs induce the distinct symptoms.

In summary, we have demonstrated that the causal agent of the necrotic symptoms exhibited in hot pepper is a virus, BBWV-K, belonging to BBWV group 2. The nucleotide sequence data for BBWV-K will be useful to initiate studies utilizing genetic engineering for the control of disease caused by BBWVs as well as the necrotic disease in hot pepper plants caused by BBWV-K.

\section{ACKNOWLEDGMENTS}

This work was supported by a grant for G7 projects from the Ministry of Science and Technology. I. S. Cutis was funded by the Brain Pool Program.

\section{LITERATURE CITED}

1. Blinov, V. M., Koonin, E. V., Gorbalenya, A. E., Kaliman, A. V., and Kryukov, V. M. 1989. Two early genes of bacteriophage T5 encode proteins containing an NTP binding sequence motif and probably involved in DNA replication, recombination, and repair. FEBS Lett. 252:47-52.

2. Dessens, J. T., and Lomonosoff, G. P. 1991. Mutational analysis of the putative catalytic triad of the cowpea mosaic virus $24 \mathrm{~K}$ protease. Virology 184:738-746.

3. Doel, T. R. 1975. Comparative properties of type, nasturtium ringspot and petunia ringspot strains of broad bean wilt virus. J. Gen. Virol. 26: 95-108.

4. Edwardson, J. R., Christies, R. G., Purcufull, D. E., and Petersen, M. A. 1993. Inclusions in diagnosing plant virus diseases. Pages 119-121 in: Diagnosis of Plant Virus Disease. R. E. F. Matthews, ed. CRC Press, Boca Raton, FL.

5. Frohman, M. A., Dush, M. K., and Martin, G. R. 1988. Rapid production of full-length cDNAs from rare transcripts: Amplification using a single gene-specific oligonucleotide primer. Proc. Natl. Acad. Sci. USA 85: 8998-9002.

6. Graves, M. V., and Roossinck, M. J. 1995. Characterization of defective RNAs derived from RNA 3 of the Fny strain of cucumber mosaic cucumovirus. J. Virol. 69:4746-4751.

7. Hillman, B. I., Carrington, J. C., and Morris, T. J. 1987. A defective interfering RNA that contains a mosaic of a plant virus genome. Cell 51:427-433.

8. Kim, J. S., and Lee, K. H. 1993. Virus disease incidence, transmission, and control in red pepper. J. Korean Capsicum Res. Coop. 2:12-40.

9. Kobayashi, Y. O., Nakano, M., Kashiwazaki, S., Naito, T., Mokoshiba, Y., Shiota, A., Kameya-Iwaki, M., and Honda, Y. 1999. Sequence analysis of RNA-2 of different isolates of broad bean wilt virus confirms the existence of two distinct species. Arch. Virol. 144:1429-1438.

10. Kuroda, T., Okumura, A., Takeda, L., Miura, Y., and Suzuki, K. 2000. Nucleotide sequence and synthesis of infectious RNA from cloned cDNA of broad bean wilt virus 2 RNA 2. Arch. Virol. 145:787-793.

11. LeGendre, N., and Matsudaria, P. T. 1989. Purification of proteins and peptides by SDS-PAGE. Pages 49-69 in: A Practical Guide to Protein and Peptide Purification for Microsequencing. P. T. Matsudaria, ed. Academic Press, New York.

12. Lim, P. O., Ryu, J. S., Lee, H. J., Lee, U., Park, Y. S., Kwak, J. M., Choi, J. K., and Nam, H. G. 1997. Resistance to tobamoviruses in transgenic tobacco plant expressing the coat protein gene of pepper mild mottle virus (Korea isolate). Mol. Cell 7:313-319.

13. Lockhart, B. E. L., and Betzold, J. A. 1982. Broad bean wilt virus in begonia in Minnesota. Plant Dis. 66:72-73.

14. Mayo, M. A., and Fritsch, C. 1994. A possible consensus sequence for VPg of viruses in the family Comoviridae. FEBS Lett. 354:129-130.

15. Nakamura, S., Iwai, T., and Honkura, R. 1998. Complete nucleotide sequence and genome organization of broad bean wilt virus 2. Ann. Phytopathol. Soc. Jpn. 64:565-568.

16. Park, Y. S., Song, O. K., Hong, S. W., Kwak, J. M., Cho, M. J., and Nam, H. G. 1994. Functional complementation of a yeast vesicular transport mutation ypt1-1 by a Brassica napus cDNA clone encoding a small GTP binding protein. Plant Mol. Biol. 26:1725-1735.

17. Poch, O., Sauvaget, I., Delarue, M., and Tordo, N. 1989. Identification of four conserved motifs among the RNA-dependent RNA polymerase encoding elements. Eur. Mol. Biol. Organ. J. 8:3867-3874.

18. Powell-Abel, P., Nelson, R. S., De, B., Hoffman, N., Rogers, S. G., Fraley, R. T., and Beachy, R. N. 1986. Delay of disease development in transgenic plants that express the tobacco mosaic virus coat protein gene. Science 232:738-748.

19. Romero, J., Huang, Q., Pogany, J., and Bujarski, J. J. 1993. Characterization of defective interfering RNA components that increase symptom severity of broad bean mottle virus infections. Virology 194: 576-584.

20. Roux, L., Simon, A. E., and Holland, J. J. 1991. Effects of defective interfering viruses on virus replication and pathogenesis in vitro and in vivo. Adv. Virus Res. 40:181-211.

21. Sambrook, J., Fritsch, E. F., and Maniatis, T. 1989. Analysis of RNA by primer extension. Pages 7.79-7.83 in: Molecular Cloning. N. Ford, C. Nolan, and M. Ferguson, eds. Cold Spring Harbor Laboratory, Cold Spring Harbor, NY.

22. Scholthof, K.-B. G., Scholthof, H. B., and Jackson, A. O. 1995. The effect of defective interfering RNAs on the accumulation of tomato bushy stunt virus proteins and implications for disease attenuation. Virology 211:324-328.

23. Scott, S. W., and Barnett, O. W. 1984. Some properties of an isolate of broad bean wilt virus from Dogwood (Cornus florida). Plant Dis. 68:983-985.

24. Shukla, D. D., Teakle, D. S., and Gough, K. H. 1980. Periwinkle, a latent host for broad bean wilt and cucumber mosaic viruses in Australia. Plant Dis. 64:802-803.

25. Shukla, D. D., Ward, W. C., and Brunt, A. A. 1994. Taxonomy. Pages 178-208 in: The Potyviridae. CAB International, Wallingford, U.K.

26. Taylor, R. H., and Stubbs, L. L. 1972. Broad bean wilt virus. Page 81 in: Description of Plant Viruses. Commonw. Mycol. Inst./Assoc. Appl. Biol., Warwick, U.K.

27. Turnbull-Ross, A. D., Reavy, B., Mayo, M. A., and Murant, A. F. 1992. The nucleotide sequence of parsnip yellow fleck virus: A plant picornalike virus. J. Gen. Virol. 73:3203-3211.

28. Uyemoto, K. J., and Provvidenti, R. 1974. Isolation and identification of two serotypes of broad bean wilt virus. Phytopathology 64:1547-1548.

29. White, K. A., Bancroft, J. B., and Mackie, G. A. 1991. Defective RNAs of clover yellow mosaic encode nonstructural/coat protein fusion products. Virology 183:479-486.

30. Xu, Z. G., Cockbain, A. J., Woods, R. D., and Govier, D. A. 1988. The serological relationships and some other properties of isolates of broad bean wilt virus from faba bean and pea in China. Ann. Appl. Biol. 113:287-296. 